độ nhạy 66,7\%; độ đặc hiệu 98,6\%; giá trị dự đoán dương tính 85,7\%; giá trị dự báo âm tính: 95,9\%. Khi kết hợp với thang điểm chẩn đoán viêm ruột thừa ở trẻ em (PAS), sẽ nâng cao hơn nữa hiệu quả của siêu âm trong chẩn đoán viêm ruột thừa.

\section{TÀI LIÊU THAM KHẢO}

1. Nguyễn Thi Minh Chính (2012). Nghiên cứu đặc điểm lâm sàng, cận lâm sàng viêm ruột thửa trẻ em dưới 5 tuô̂i. Luận án bác sĩ chuyên khoa cấp II, Trường đại học Y Hà Nội, Hà Nô̂i.

2. Bùi Đức Hậu (2015). Viêm ruột thừa trẻ em: Lâm sàng, cận lấm sàng và kết quả điêu trị. Tạp chí y hoc Viêt Nam. 2(420): 51-56.

3. Phan Thanh Lương, Trân Ngọc Bích, Vũ Huy Nùng (2003). Nghiên cứu đắc điểm lâm sàng cận lấm sàng và giải phẫu bệnh lý trong viêm ruột thừa cấp ở trẻ em. Tạp chí Y học thực hành. 2: 27-32.
4. Dương Văn Mai (2016). Nghiên cứu kết quả điều trị viêm ruột thừa cấp ở trẻ em bằng phẩu thuật nôi soi tai bênh viên đa khoa tỉnh Phú Tho. Luận vắn bác sĩ nội trú, Đ̇ại học Y dược Thái Nguyên.

5. Pham Thị Minh Rang, Pham îê An (2012). Giá trị thang điểm Alvarado và siêu âm trong chẩn đoán viểm ruột thừa cấp ở trẻ em. Nghiên cứu y hoc. 16(1): 96-101.

6. Almaramhy HH (2017). Acute appendicitis in young children less than 5 years: review article. Ital J Pediatr. 43(1): 15.

8. Carpenter JL, Orth RC, Zhang $W$ et al (2017). Diagnostic Performance of US for Differentiating Perforated from Nonperforated Pediatric Appendicitis: A Prospective Cohort Study. Radiology. 282(3): 833-841.

9. Estey A, Poonai N, Lim R (2013). Appendix not seen: the predictive value of secondary inflammatory sonographic signs. Pediatr Emerg Care. 29(4): 435-439.

\title{
SỰ ẢNH HƯởNG CỦA KÍCH THƯớC VÀ TỶ LÊ TẢI TRÊN SỰ GIẢI PHÓNG DƯợC CHẤT CỦA VI CÂUU XỐP CHỨ METRONIDAZOL
}

\section{TÓM TẮT}

Muc tiêu: Thiết lập các thông số điêu chế phù hợp để tạo ra các vi cầu xốp chứa dược chất metronidazol có đắc tính kích thước và tỉ lế tải khác nhau. Từ đó, khảo sát ảnh hưởng của các đặc tính này đến khả năng kiểm soát sự giải phóng và động học giải phóng dược chất từ vi câu xốp. Đối tượng và phương pháp: Vi câu xốp ethyl cellulose chứa metronidazol là đối tượng của nghiên cứu. Vi cầu được điều chế bằng phương pháp bốc hơi dung môi từ nhũ tương. Các đặc tính của vi cầu được nghiên cứu là kích thước trung bình, tỷ lệ tải sự ảnh hưởng của chúng trên khả năng và động học giải phóng dược chất. Kết quả: Kích thước và tỷ lệ tải của vi cầu tạo thành có thể được kiểm soát thông qua nồng độ ethyl cellulose, nồng độ dược chất phân tán trong pha dâu, nồng đố chất ổn đinh nhũ tương hoăc các thông số quy trình như tốc độ và thời gian đồng nhất hóa. Vi câu có kích thước lớn hơn, tỷ lệ tải cao hơn cho thây khả năng giải phóng dược chất nhanh hơn. Dược chất được giải phóng khỏi vi cầu nhờ cơ chế khuếch tán kết hợp với sự bào mòn của chuỗi polyme. Kết luận: Kích thước và tỷ lệ tải của vi câu xốp ethyl cellulose có thể được kiểm soát thông qua các thông số điều chế và từ đó có thể giúp kiểm soát khả năng giải phóng dược chất của vi cầu. Tư khóa: vi câu xốp ethyl cellulose, metronidazole, giải phóng dược chất

${ }^{1}$ Dại học Y Dược Tp. Hồ Chí Minh

Chịu trách nhiệm chính: Lê Minh Quân

Email: leminhquan@ump.edu.vn

Ngày nhận bài: 1.11.2021

Ngày phản biện khoa học: 27.12.2021

Ngày duyệt bài: 4.01.2022
Lê Minh Quân ${ }^{1}$, Tiêu Du Trương ${ }^{1}$, Lê Hậu ${ }^{1}$

\section{SUMMARY}

EFFECT OF PARTICLE MEAN SIZE AND

ENCAPSULATION RATIO ON THE DRUG

RELEASE OF METRONIDAZOLE-LOADED

POROUS MICROSPHERE

Objective: Formulate various porous microsphere batches with different particle mean sizes and encapsulation ratios. Those microspheres would be employed to investigate the effect of the spheres' characteristics on their drug release. Subjects and methods: Porous ethylcellulose-based microspheres containing metronidazole were studied. The microspheres were prepared by emulsification solvent evaporation method. The spheres' mean size and encapsulation ratios and their effects on drug release rates and kinetics would be focused on. Results: The resultant microspheres' size and drug loading ratio could be controlled through polymer concentration, drug concentration in the oil phase, emulsion stabilizer concentration or process parameters such as homogenization speed and time. Microspheres with a larger size or higher loading ratio presented faster drug release. Drugs are released from microspheres by a diffusion mechanism combined with polymer chain erosion. Conclusion: The size and drug encapsulation ratio of ethyl cellulose-based porous microspheres could be controlled through parameter modulation and could help control the drug release profile of the microspheres.

Keywords: porous microsphere ethyl cellulose, metronidazole, drug release

I. ĐẶT VẤN ĐỀ

Vi cầu (microsphere) là các tiểu phân hình 
câu kích thước từ 1 - 1000 m, chứa dược chất được phân tán đồng nhất trong khung polyme [1]. Uuu điểm quan trọng của vi cầu thể hiện ở khả năng kiểm soát sự giải phóng dược chất (GPDC) dù có kích thước nhỏ hàng micromet. Tuy nhiên, do có độ xốp cao, khả năng kiểm soát và kéo dài sự giải phóng dược chất của vi cầu xốp bị hạn chể. Điều này trở thành thử thách cho các nhà nghiên cứu vi câu xốp hiện nay.

Khả năng kiểm soát sự giải phóng dược chất phụ thuộc vào kích thước trung bình, tỷ lệ tải dược chất và độ xốp của vi cầu [2]. Kích thước trung bình và tỷ lệ tải dược chất trở thành hai đặc tính quan trọng nhất [2]. Tuy nhiên, cho đến nay chưa có nhiều dữ liệu nghiên cứu cho thấy ảnh hưởng của các đặc tính này trên khả năng kiểm soát giải phóng dược chất của vi cầu xốp có tương tự như các vi cầu đặc hay không. Do đó, nghiên cứu này được thực hiện nhằm thiết lập các thông số điều chế phù hợp để tạo ra các vi câu xốp chứa dược chất metronidazol có đặc tính kích thước và tỷ lệ tải khác nhau. Và khảo sát ảnh hưởng của các đặc tính này đến khả năng kiểm soát sự giải phóng và động học giải phóng dược chất từ vi cầu xốp.

\section{II. ĐỐI TƯợNG VÀ PHƯƠNG PHÁP NGHIÊN CỨU}

2.1. Đối tượng nghiên cứu và nguyên vật liệu. Metronidazol (Trung Quốc) đạt tiêu chuẩn USP/NF, ethyl cellulose $45 \mathrm{cps}(\mathrm{EC})$ được cung cấp bởi Colorcon (Singapore). Các tá dược, dung môi khác dùng trong điều chế gồm Poly(vinyl alcol) (PVA) (Duksan, Hàn Quốc), dicloromethan (DCM) (VinaChemsol, Việt Nam) đạt tiêu chuẩn dược dụng.

2.2. Phương pháp điêu chế vi câu. Vi cầu được điều chế bằng phương pháp bốc hơi dung môi từ nhũ tương [3]. Hòa tan một lượng xác định ethyl cellulose trong $20 \mathrm{ml}$ dichloromethan tạo thành pha dầu $(0)$ có nồng độ từ 40 - 60 $\mathrm{mg} / \mathrm{ml}$. Đồng nhất hóa tiểu phân metronidazol (S) vào pha dầu để tạo hỗn dịch $\mathrm{S} / \mathrm{O}$ trước khi nhũ hóa hỗn hợp này vào $40 \mathrm{ml}$ dung dịch PVA có nồng độ xác định. Thêm $200 \mathrm{ml}$ dung dịch PVA $0,5 \%$ và tiếp tục khuây với tốc độ 1000 rpm trong 60 phút. Lọc, rửa, sấy vi cầu thu được ở nhiệt độ $50^{\circ} \mathrm{C}$ trong 180 phút. Bảo quản trong bình hút ẩm cho các phân tích tiếp theo.

2.3. Phương pháp đánh giá đặc tính vi câu. Xác định tỷ lệ tải dược chất: Cân chính xác
$20 \mathrm{mg}$ vi cầu vào bình định mức $50 \mathrm{~mL}$, hòa tan bằng $2 \mathrm{ml}$ dichloromethan. Thêm vào bình $30 \mathrm{ml}$ nước cất và siêu âm 30 phút trước khi bổ sung nước cất đến vạch. Lọc hỗn hợp qua màng 0,45 $\mu \mathrm{m}$ và xác định nồng độ metronidazol trong mẫu thử bằng phương pháp đo quang phổ hấp thu UV ở bước sóng 320 nm, mẫu so sánh là mẫu được xử lý tương tự trên vi câu không chứa hoạt chất.

Tỷ lệ tải $(\%)=\frac{\text { Lượng dược chất trong vi cầu }(\mathrm{mg})}{\text { Lượng vi cầu }(\mathrm{mg})} \times 100$

Xác định kích thước: Kích thước trung bình của vi cầu được xác định bằng thực nghiệm trên thiết bị đo kích thước hạt Malvern Mastersizer 3000.

Xác định độ cầu: soi khô các mấu MS trên kính hiển vi quang học Olympus với lượng mẫu khoảng $50 \mathrm{mg} /$ lân đo. Chụp hình và xác định độ cầu của từng tiểu phân bằng phần mềm ImageJ, tính giá trị trung bình về độ cầu từ kết quả phân tích 50 tiểu phân [4].

Xác định hình thái vi cầu: bằng phương pháp chụp ảnh hiển vi điện tử quét (SEM) trên thiết bị FESEM S4800.

2.4. Phương pháp đánh giá khả năng giải phóng dược chất. Thử nghiệm GPDC được tiến hành bằng thiết bị giỏ quay. Cân 200 mg vi cầu vào nang cứng số 0 . Viên nang được cho vào $500 \mathrm{ml}$ nước cất ở nhiệt độ $37,0 \pm 0,5^{\circ} \mathrm{C}$ và khuấy với tốc độ 100 rpm. Tại mỗi thời điểm (1, $2,3,4,6,8,10,12,14,16,18,20,22,24,26$ giờ), lấy $5 \mathrm{ml}$ mẫu thử và bổ sung $5 \mathrm{ml}$ nước cất. Lợ mấu thử qua màng lọc $0,45 \mu \mathrm{m}$ và định lượng bằng phương pháp quang phổ hấp thu UV ở bước sóng $320 \mathrm{~nm}$.

Dữ liệu giải phóng được kiểm định tính tương thích với các mô hình động học bậc 0 , bậc 1 , Higuchi, Hixson - Crowell và Korsmeyer - Peppas dựa trên thuật toán GOF (goodness of fit) lập trình trực tiếp trên ngôn ngữ lập trình MatLab. Tính tương thích được xác định khi $\mathrm{R}^{2}$ lớn hơn 0,90 và sai số của phép ước lượng không lớn hơn 0,3 . Trong trường hợp phép kiểm định phù hợp với mô hình Korsmeyer - Peppas, các phân tích số mũ $\mathrm{n}$ và hệ số tác động của sự khuếch tán và bào mòn polyme sẽ được thực hiện dựa trên phương trình Peppas - Sahlin.

\section{KẾT QUẢ NGHIÊN CỨU}

3.1. Ảnh hưởng của thành phân tá dược và thông số quy trình điêuu chế đến kích thước và tỷ lệ tải của vi câu

Bảng 1. Thí nghiệm khảo sát các yếu tố công thức trong điều chế vi cầu

\begin{tabular}{|c|c|c|c|c|c|c|}
\hline & \multicolumn{3}{|c|}{ Thông số đî̀u chế } & \multicolumn{3}{|c|}{ Đặc tính vi câu } \\
\hline & $\begin{array}{l}\text { Nông độ } \\
\text { polyme }\end{array}$ & $\begin{array}{l}\text { Nồng độ } \\
\text { dược chẩt }\end{array}$ & $\begin{array}{l}\text { Nông độ chất } \\
\text { ổn định }\end{array}$ & $\begin{array}{c}\text { Tỷ lề } \\
\text { tải }\end{array}$ & $\begin{array}{l}\text { Kích thước vi } \\
\text { câu }(\mu \mathrm{m})\end{array}$ & Độ câu \\
\hline
\end{tabular}




\begin{tabular}{|l|c|c|c|c|c|c|}
\hline & $\mathbf{( m g / m l )}$ & $\mathbf{( m g / m l )}$ & $\mathbf{( \% )}$ & $\mathbf{( \% )}$ & & \\
\hline CT1 & $\mathbf{4 0}$ & 600 & 1 & 7,98 & 121,36 & 0,87 \\
\hline CT2 & $\mathbf{5 0}$ & 600 & 1 & 8,06 & 263,15 & 0,78 \\
\hline CT3 & $\mathbf{6 0}$ & 600 & 1 & 12,62 & 362,10 & 0,74 \\
\hline CT4 & 50 & $\mathbf{4 0 0}$ & 1 & 7,86 & 218,92 & 0,83 \\
\hline CT5 & 50 & $\mathbf{8 0 0}$ & 1 & 0,44 & 205,68 & 0,80 \\
\hline CT6 & 50 & $\mathbf{6 0 0}$ & 1,5 & 3,71 & 96,80 & 0,85 \\
\hline CT7 & 50 & $\mathbf{6 0 0}$ & 2 & 1,52 & 59,86 & 0,85 \\
\hline
\end{tabular}

Nhận xét: Ảnh hưởng của ba yếu tố thuộc về thành phần tá dược đã khảo sát gồm nồng độ ethyl cellulose trong pha dầu, nồng độ metronidazol trong hỗn dịch $\mathrm{S} / \mathrm{O}$, nồng độ chất ổn định trong giai đoạn nhũ tương hóa. Kết quả đánh giá tính chất vi câu tạo thành tương ứng được trình bày trong bảng 1 .

Bảng 2. Thí nghiệm khảo sát các thông số quy trinh điều chế vi cầu

\begin{tabular}{|c|c|c|c|c|c|}
\hline & \multicolumn{2}{|c|}{ Thông số bào chế } & \multicolumn{3}{c|}{ Đặc tính vi câu } \\
\hline & $\begin{array}{c}\text { Tốc đố đồng nhất } \\
\text { hóa (rpm) }\end{array}$ & $\begin{array}{c}\text { Thời gian đồng } \\
\text { nhất hóa (phút) }\end{array}$ & $\begin{array}{c}\text { Tỷ lệ tải } \\
\text { (\%) }\end{array}$ & $\begin{array}{c}\text { Kích thước } \\
\text { vi câu ( } \boldsymbol{\mu m})\end{array}$ & Độ câu \\
\hline CT7 & 5000 & 2 & 10,85 & 104,52 & 0,83 \\
\hline CT8 & 5400 & 2 & 9,93 & 212,12 & 0,80 \\
\hline CT1 & 6000 & 2 & 8,06 & 263,15 & 0,78 \\
\hline CT9 & 5000 & 3 & 10,90 & 149,57 & 0,82 \\
\hline CT10 & 5000 & 4 & 10,96 & 128,25 & 0,77 \\
\hline
\end{tabular}

Nhận xét: Đối với các thông số quy trình, ảnh hưởng riêng phần của tốc độ đồng nhất hóa và thời gian đồng nhất hóa đã được đánh giá. Kết quả phân tích vi cầu tạo thành từ các thí nghiệm được trình bày trong bảng 2.

3.2. Ảnh hưởng của kích thước vi câu trên khả năng kiểm soát sự giải phóng dược chất. Ảnh hưởng của kích thước đến khả năng GPDC được thực hiện bằng cách thử độ hòa tan của các vi cầu có tỷ lệ tải xấp xỉ nhau đồng thời kích thước trung bình khác nhau, đại diện cho các mức thấp (CT7, kích thước 104,52 $\mu \mathrm{m})$ và mức cao (CT8, kích thước 212,11 $\mu \mathrm{m}$ )

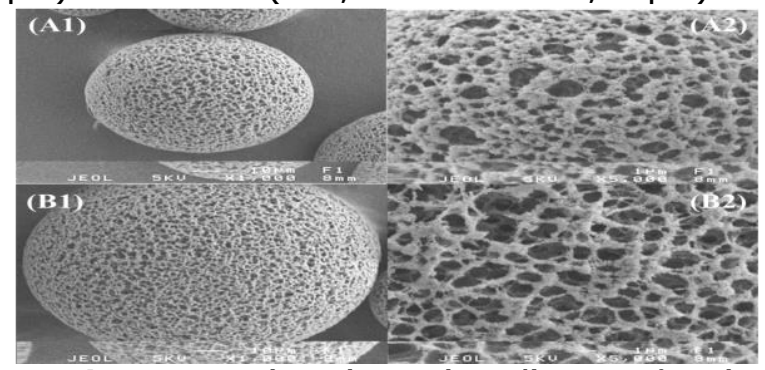

Hình 2. So sánh hinh thái vi cầu tạo bởi thí nghiệm CT7 (A1-A2) và CT8 (B1-B2) (ở các độ phóng đại 1000 và 5000 lần)

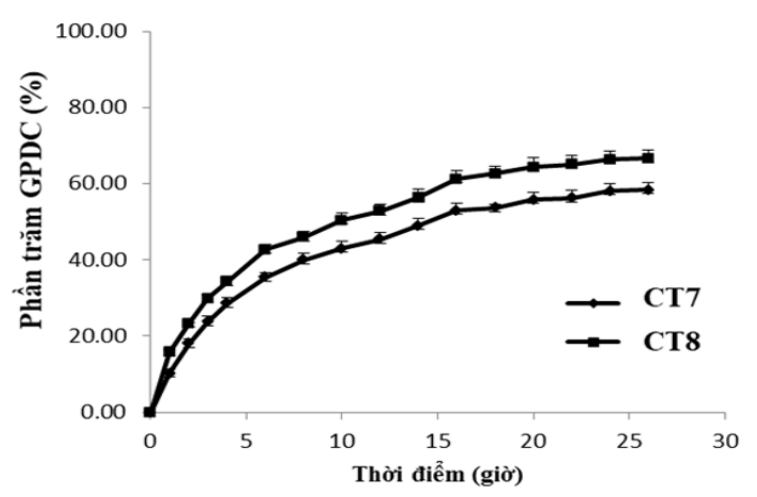

Hinh 3. Phần trăm GPDC theo thời gian của vi cầu tạo bởi CT7 so với CT8

Nhân xét: Các vi cầu thử nghiệm có cùng đặc điểm hình thái với cấu trúc xốp toàn thể và các lỗ xốp tạo thành mạng lưới thông nhau. Sự khác biệt về kích thước và khả năng GPDC được thể hiện ở Hình 2 và hình 3.

Bảng 3. Giá trị $R^{2}$ theo từng mô hình động học của công thức CT7 và CT8

\begin{tabular}{|l|c|c|c|c|c|c|c|c|c|c|}
\hline & $\begin{array}{c}\text { Bậc } \\
\mathbf{j}\end{array}$ & $\begin{array}{c}\text { Bậc } \\
\mathbf{i}\end{array}$ & Higuchi & $\begin{array}{c}\text { Hixson- } \\
\text { Crowell }\end{array}$ & \multicolumn{2}{|c|}{ Korsmeyer-Peppas } & \multicolumn{3}{|c|}{ Peppas-Sahlin } \\
\hline & $\mathrm{R}^{2}$ & $\mathrm{R}^{2}$ & $\mathrm{R}^{2}$ & $\mathrm{R}^{2}$ & $\mathrm{R}^{2}$ & $\mathrm{k}$ & $\mathrm{n}$ & $\mathrm{k}_{1}$ & $\mathrm{k}_{2}$ & $\mathrm{~m}$ \\
\hline CT7 & 65,4 & 83 & 97,7 & 77,8 & 98,7 & 0,15 & 0,44 & 0,16 & $-0,005$ & 0,45 \\
\hline CT8 & 57,8 & 82,5 & 96,7 & 75,6 & 99,5 & 0,18 & 0,44 & 0,19 & $-0,004$ & 0,45 \\
\hline
\end{tabular}

Nhận xét: Dữ liệu GPDC in vitro của các công thức CT7 và CंT8 được kiểm định tính tương thích lần lượt với các mô hình động học. Kết quả giá trị của các hệ số tính toán ở mỗi mô hình được trình bày ở Bảng 3.

3.3. Ảnh hưởng của tỷ lệ tải trên khả năng kiểm soát sự giải phóng dược chất của vi câu 


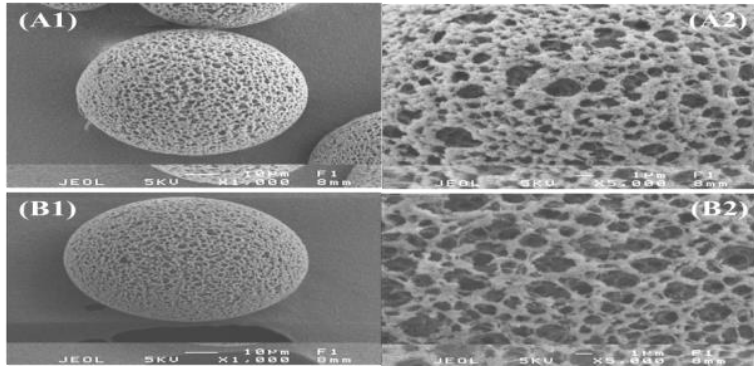

Hình 4. So sánh hinh thái vi cầu tạo bởi CT7 (A1-A2) và $C T 1$ (B1-B2)

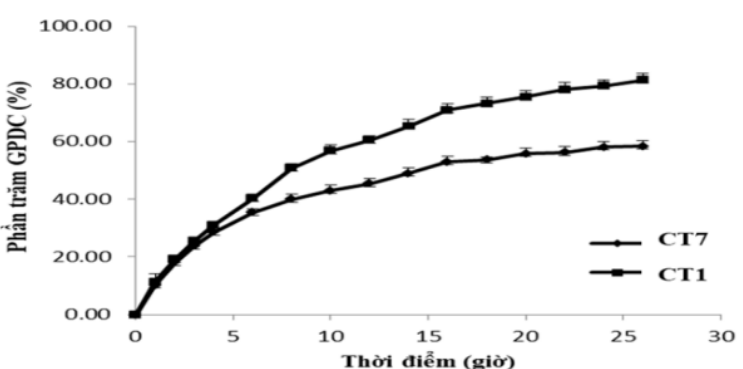

Hinh 5. Phần trăm GPDC theo thời gian của vi cầu tạo bởi CT1 so với CT7

Nhận xét: Ảnh hưởng của tỷ lệ tải được khảo sát theo hướng chọn các công thức có tie lệ tải khác nhau đồng thời kích thước trung bình xấp xỉ nhau để đánh giá GPDC in vitro. Công thức được lựa chọn đánh giá là $\mathrm{CT} 1$ (tương ứng với mức tỷ lệ tải thấp 7,97\%) và CT7 (tương ứng với mức tỷ lệ tải cao 10,85\%). Hình thái học vi câu và đồ thị GPDC theo thời gian được thể hiện ở Hình 4 và hình 5.

Bảng 4. Giá trị $R^{2}$ theo từng mô hình động học của công thức CT1 và CT7

\begin{tabular}{|c|c|c|c|c|c|c|c|c|c|c|}
\hline & Bậc 0 & Bậc 1 & Higuchi & $\begin{array}{c}\text { Hixson- } \\
\text { Crowell }\end{array}$ & \multicolumn{3}{|c|}{$\begin{array}{c}\text { Korsmeyer- } \\
\text { Peppas }\end{array}$} & \multicolumn{3}{c|}{ Peppas-Sahlin } \\
\hline & $\mathrm{R}^{2}$ & $\mathrm{R}^{2}$ & $\mathrm{R}^{2}$ & $\mathrm{R}^{2}$ & $\mathrm{R}^{2}$ & $\mathrm{k}$ & $\mathrm{n}$ & $\mathrm{k}_{1}$ & $\mathrm{k}_{2}$ & $\mathrm{~m}$ \\
\hline CT1 & 79,6 & 97,1 & 98,7 & 93,1 & 99,7 & 0,12 & 0,62 & 0,073 & 0,053 & 0,425 \\
\hline CT7 & 65,4 & 83 & 97,7 & 77,8 & 98,7 & 0,15 & 0,43 & 0,16 & $-0,005$ & 0,45 \\
\hline
\end{tabular}

Nhận xét: Dữ liệu GPDC in vitro của các công thức CT1 và CT7 được kiếm định tính tương thích lần lượt với các mô hình động học. Kết quả giá trị của các hệ số tính toán ở mối mô hình được trình bày ở Bảng 4.

\section{BÀN LUÂN}

4.1. Ảnh hưởng của thành phân tá dược và thông số quy trình điêu chế đến kích thước và tỷ lẹ tải của vi câu

Đối với thành phân tá dược. Công thức $\mathrm{CT} 1, \mathrm{CT} 2$ và $\mathrm{CT} 3$ được thiết kể có nồng độ polyme tăng dần từ $40 \%$ đến $60 \%(\mathrm{kl} / \mathrm{tt})$ trong dung môi, các điều kiện điều chế khác giữ nguyên không đổi. Kết quả khi tăng nồng độ polyme, tỷ lệ dược chất tải được tăng từ 7,98\% (CT1) đến $12,62 \%$ (CT3); kích thước trung bình của vi cầu cũng tăng tương ứng trong khoảng 121,36$362,10 \mu \mathrm{m}$; tuy nhiên độ cầu có xu hướng giảm.

Khi nồng độ polyme trong pha hữu cơ $(0)$ ở mức cao, polyme nhanh chóng đạt trang thái bão hòa và hóa rắn nhanh khi dung môi bị tách loại vào pha ngoại. Dẫn đến vi cầu có kích thước trung bình lớn hơn, dược chất bị bắt giữ trong khung polyme nhanh hơn (ít bị thất thoát ra pha ngoại) và làm tăng tỷ lệ tải dược chất của cầu [3]. CT2 có kích thước vi cầu nằm trong khoảng

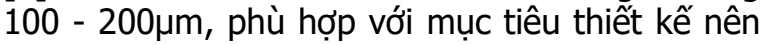
nông độ polyme $50 \%$ được lựa chọn cho bước nghiên cứu tiếp theo.

Nồng độ dược chất phân tán trong pha hữu cơ đã được chứng minh là có ảnh hưởng đến tỷ lệ tải của vi câu tạo thành [3]. CT4 và CT5 được thiết kế với nồng độ dược chất lần lượt là $400 \mathrm{mg} / \mathrm{ml}$ và $800 \mathrm{mg} / \mathrm{ml}$ để so sánh với CT2 với
600 mg/ml (các điều kiện điều chế khác tương tự nhau). Kết quả đánh giá vi cầu cho thây kích thước và độ câu khác nhau không có ý nghĩa thống kê $(p=0,1991>0,05)$ giữa $C T 2, C T 4$ và CT5. Đối với tỷ lệ tải, sự khác biệt không có ý nghĩa $(p=1>0,05)$ giữa vi cầu tạo bởi công thức có nồng độ dược chất 400 mg/ml (CT4; $7,86 \%)$ và $600 \mathrm{mg} / \mathrm{ml}(\mathrm{CT} 2 ; 8,06 \%)$. Tuy nhiên khi tăng nồng độ metronidazol trong pha phân tán lên $800 \mathrm{mg} / \mathrm{ml}$, tỷ lệ tải giảm đáng kể còn $0,44 \%$ (CT5). Trong quá trình thực nghiệm ở CT5, quan sát thấy các tiểu phân dược chất dù được phân tán tốt trong pha hữu cơ (O), nhưng dễ dàng tách lớp và thất thoát (leaking) về pha ngoại $(W)$. Điều này có thể do đặc tính thân nước và nồng độ cao của metronidazol trong các giọt của pha phần tán.

Ảnh hưởng của nồng độ PVA trên tính chất vi câu tạo thành được khảo sát ở các mức $1 \%$ $1,5 \%-2 \%$ tương ứng với $\mathrm{CT} 2, \mathrm{CT} 6$ và $\mathrm{CT} 7$. Việc tăng nồng độ chất nhũ hóa $1 \%$ đến $2 \%$ dẫn đển kích thước vi câu tạo thành giảm mạnh tương ứng

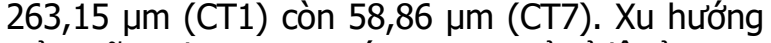
giảm cũng được quan sát tương tự ở tỷ lệ tải.

Đối với thông số quy trình. Tốc độ đồng nhất hóa được khảo sát trong khoảng 5000 6000 rpm. Sự thay đổi tốc độ đồng nhất hóa trong khoảng khảo sát dẫn đến sự biến thiên khác nhau của tỷ lệ tải và kích thước vi câu. Tỷ lệ tải dược chất giảm từ 10,85\% (CT7) còn 
8,06\% (CT2) khi tăng tốc độ nhũ hóa. Kích thước vi câuu tăng trong khoảng 104,52 - 263,15 um khi tốc độ tăng từ 5000 rpm lên 6000 rpm.

Thiết kế các thí nghiệm thay đổi thời gian đồng nhất hóa trong khoảng 2 - 4 phút cho thấy việc thay đổi thời gian nhũ hóa không có tác động đáng kể đến tỷ lệ metronidazol. Tuy nhiên, kích thước vi cầu có biến thiên đồng biến với thời gian khảo sát. Cụ thể, khi tăng thời gian đồng nhất hóa từ 2 phút lên 4 phút, vi cầu tạo thành có kích thước tăng nhẹ từ 104,52 $\mu \mathrm{m}$ (CT7) lên

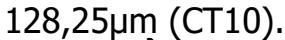

4.2. Ảnh hưởng của kích thước vi câu trên khả năng kiểm soát sự giải phóng dược chất. Kết quả đánh giá khả năng GPDC của công thức CT7 và CT8 cho thấy phần trăm metronidazol giải phóng sau 26 giờ của các công thức đạt trong khoảng $60 \%-70 \%$. Sự GPDC có sự khác biệt không lớn ở giữa hai công thức. $\mathrm{V}$ cầu kích thước lớn hơn (CT8) có tốc độ giải phóng nhanh hơn so với vi cầu có kích thước nhỏ hơn (CT7). Kết quả này không có tính phổ biến vì vi cầu kích thước càng lớn thường có diện tích tiếp xúc nhỏ, giải phóng chậm.

Có thể giải thích kết quả thu được dựa vào đặc tính xốp toàn thể của vi cầu. Các nghiên cứu đã công bố cho thấy nếu vi cầu xốp có độ xốp như nhau, sự GPDC có thể không phụ thuộc vào kích thước [5],[6]. Hình ảnh SEM thu được đều cho thấy bề mặt các vi cầu có cấu trúc xốp với lỗ xốp thông nhau. Trong nghiên cứu này, vi cầu $C T 7$ có độ xốp thấp hơn (thể tích xốp đo bằng phương pháp BET là khoảng $8 \mathrm{~mm}^{3} / \mathrm{g}$ ), bên trong vi câu có sự sắp xếp các chuỗi polyme chặt chẽ hơn, làm chậm quá trình khuếch tán dược chất ra ngoài. Ngược lại, vi câu CT8 (thể tích xốp $14 \mathrm{~mm}^{3} / \mathrm{g}$ ) có độ xốp cao hơn và giải phóng nhanh hơn.

Dữ liệu GPDC in vitro từ cả hai công thức đều cho thây sự tương thích với mô hình Korsmeyer Peppas. Với tham số $\mathrm{n}$ có giá tri đều là 0,44 , dược chất giải phóng theo cơ chế hốn hợp (anomalous diffusion) bao gồm sự khuếch tán của dược chất và sự bào mòn khung ethyl cellulose. Hai cơ chế này cùng đồng thời tác động có ý nghĩa lên động học giải phóng của vi cầu.

4.3. Ảnh hưởng của kích thước vi câu trên khả năng kiểm soát sự giải phóng dược chất. Dữ liệu về độ GPDC cho thấy sự khác biệt giữa hai công thức khảo sát. Ở thời điểm 5 giơo, đồ thị GPDC là tương tự nhau. Sự khác biệt trong tốc độ GPDC bắt đâuu thể hiện rố từ thời điểm 10 giờ, dược chất giải phóng nhanh hơn ở công thức có tỷ lệ tải cao. Tỷ lệ GPDC ở công thức có tỷ lệ tải cao (CT7) đạt khoảng
$60 \%$, vi cầu có tỷ lệ tải thấp (CT1) chỉ giải phóng khoảng $40 \%$ dược chất. Ở giờ thứ 26 , khi vi câu CT7 giải phóng được trên $80 \%$ dược chất, vi cầu từ công thức CT1 chỉ giải phóng khoảng $57 \%$. Kết quả này đồng thuận với nghiên cứu của $M$. Jelvehgari và cộng sự [7]. Theo đó, dược chất sau khi được giải phóng ra môi trường thử nghiệm để lại các kênh khuếch tán trên vi cầu. Vi cầu có tỷ lệ tải càng cao, quá trình tạo kênh khuếch tán diễn ra càng nhanh, tiếp tục thúc đẩy sự giải phóng nhanh dược chất. Như vậy, tốc độ GPDC tương quan thuận với tỷ lệ tải trong nghiên cứu này.

Kết quả cho thấy dữ liệu GPDC của cả hai mẫu vi cầu đều tương thích với mô hình Korsmeyer Peppas. Tham số $n$ lần lượt là 0,62 và 0,43 cho phép xác định dược chất được giải phóng theo cơ chế hỗn hợp. Trong đó, sự khuếch tán của dược chất và sự bào mòn khung đồng thời tác động lển động học giải phóng của vi cầu.

\section{KẾT LUÂ̂N}

Ảnh hưởng của tỷ lệ tải dược chất và kích thước vi cầu trên khả năng kiểm soát sự GPDC và động học của quá trình này. Vi cầu có kích thước lớn hơn, tỷ lệ tải cao hơn sẽ có khả năng GPDC nhanh trong khoảng thời gian ngắn hơn. Kết quả nghiên cứu cung cấp thêm bằng chứng thực nghiệm góp phần giải thích các giải pháp kiểm soát sự GPDC từ vi cầu xốp.

LỜI CẢM ƠN. Nghiên cứu này được tài trợ bởi Đại học Y Dược Thành phố Hồ Chí Minh theo hợp đồng nghiên cứu số 37/2019/HĐ-ĐHYD.

\section{TÀI LIỆU THAM KHẢO}

[1] Park J., Ye M., Park K. (2005), "Biodegradable polymers for microencapsulation of drugs", Molecules, 10(1), 146-161.

[2] Minh-Quan L., Gimel J.C, Garric X., eta al. (2020), Modulation of protein release from pentablock copolymer microspheres, 152, 175-182.

[3] Phan Thị Kim Phưng, Lê Hậu, Lê Minh Quân (2020), Nghiên cứu bào chể vi cầu metformin hydroclorid giải phóng kéo dài bằng phương pháp bốc hơi dung môi từ nhũ tương, Tạp chí Dược học, 6, 40-45.

[4] Rough S. L., Wilson D. I., and Zhang M. (2014), "The evolution of pellet size and shape during spheronisation of an extruded microcrystalline cellulose paste", Chemical Engineering Research and Design, 92(11), 2413-2424.

[5] P. Horcajada, A. Rámila, J. Pérez-Pariente, M. Vallet-Regı (2004), "Influence of pore size of MCM-41 matrices on drug delivery rate", Microporous and Mesoporous Materials. 68 (1-3), pp 105-109.

[6] Andreas Bertz, Stefanie Wöhl-Bruhn, Sebastian Miethe, et al. (2013), "Encapsulation of proteins in hydrogel carrier systems for controlled drug delivery: Influence of network 
structure and drug size on release rate", Journal of Biotechnology. 163 (2), pp 243-249.

[7] M. Jelvehgari, A. Nokhodchi, M. Rezapour, H. Valizadeh (2010), "Effect of formulation and processing variables on the characteristics of tolmetin microspheres prepared by double emulsion solvent diffusion method", Indian journal of pharmaceutical sciences. 72 (1), pp. 72-78.

\section{ĐÁNH GIÁ HIÊU QUẢ CỦA CÔNG TÁC CHĂM SÓC VÊ SINH RĂNG MIÊNGG TRƯớC PHẪU THUÂTT Ở BỆNH NHÂN CHẤN THƯƠNG HÀM MĂT}

\section{TÓM TẮT}

Đắt vấn đề: Trong chấn thương vùng hàm măt, do có cấu trúc giải phẫu liên quan trực tiếp đển khoang miệng nên nguy cơ nhiễm trùng cao, gây khó khăn cho công tác điễu trị. Công tác chăm sóc vệ sinh răng miêng trước phấu thuật đối với bênh nhân chấn thương hàm mặt là việc làm cân thiết để giảm đau nhức vùng miêng, làm giảm nguy cơ nhiểm trùng, tăng cường hiệu quả điều trị. Đối tượng và phương pháp: Nghiên cứu mô tả tiến cứu trên 627 bệnh nhân chấn thương hàm mặt ở Trung tâm Răng Hàm Mặt, BVTW Huế năm từ tháng 1/2020 đến tháng 10/2020. Kết quả: Độ tuổi thường gặp là 18-39 (51,2\%), nam giới $414(66 \%)$, nữ giới $213(34 \%)$, chấn thương hàm mặt thường do tai nạn giao thông $(82,5 \%)$. Triệu chứng thường gặp là đau nhức $(71,3 \%)$, sưng nề $68,9 \%)$, há miệng hạn chế $(67 \%)$, biến dạng mặt $(49,8 \%)$ và chảy máu miệng $(35,9 \%)$. Các phương pháp chăm sóc răng miêng thường được sử dụng là hướng dẫn vệ sinh răng miệng $(100 \%)$, cạo cao răng $(92,2 \%)$, điều trị viêm nha chu bằng laser diode $(72,9 \%)$. Kết quả điều trị đạt được: tốt 95,9\%, khá $4,1 \%(p<0,05)$. Kết luận: Bệnh nhân chấn thương hàm mặ̆t cần được chăm sóc răng miệng trước phẫu thuật phù hợp để đạt kết quả điều trị tốt hơn và làm tăng sự hài lòng của người bệnh. mặt

Tư khoá: vệ sinh răng miệng, chấn thương hàm

\section{SUMMARY \\ EVALUATING OUTCOMES OF ORAL HEALTH CARE FOR PREOPERATIVE PATIENTS WITH MAXILLO-FACIAL TRAUMA}

Introduction: In patients with maxillo-facial trauma, since the anatomical structure of maxillo-facial region directly related to the oral cavity, the risk of infection is high, making it more difficult to treat. The oral health care for preoperative patients with maxillofacial trauma needs to be treated to minimize oral sore and the risk of infection, as well as to enhance treatment efficiency. Materials and methods: A descriptive progressive study was conducted on 627

*Trt Răng hàm mặt, Bệnh viện Trung ương Huế Chịu trách nhiệm chính: Nguyễn Hồng Lợi

Email: drloivietnam@yahoo.com.vn

Ngày nhân bài: 25.10.2021

Ngày phản biện khoa học: 27.12.2021

Ngày duyệt bài: 4.01.2022

\section{Nguyễn Hồng Lọi*, Nguyễn Thị Kim Phượng*}

patients with maxilla-facial trauma patient in OdontoStomatology Center, Hue Central Hospital from January 2020 to October 2020. Results: Average age group of patients was $18-39$ years old $(51.2 \%)$, of which 414 males $(66 \%)$ and 213 females $(34 \%)$. The traffic accidents were the most common causes of maxilla-facial trauma (82.5\%). Common clinical symptoms included pain $(71.3 \%)$, swelling $(68.9 \%)$, limitation of mouth opening $(67 \%)$, face deformation $(49.8 \%)$ and bleeding (35.9\%). The most commonly used oral health care methods consisted of oral hygiene instructions (100\%), scrape tartar (92.2\%), and the use of diode laser in periodontitis treatment $(72.9 \%)$. Our study showed that the treatment outcomes were good (95.9\%) and fairly good (4.1\%) $(p<0.05)$. Conclusion: Maxillo-facial trauma patients before operating need to be treated by proper oral health care methods to reach better treatment outcomes, and as well as improve satisfaction of patients.

Keywords: oral health care, maxillo-facial trauma

\section{I. ĐẶT VẤN ĐỀ}

Chấn thương hàm mặt là tai nạn thường gặp và ngày càng gia tăng. Trên thế giới, các nghiển cứu cho thây chấn thương hàm măăt chiếm tỷ lệ khá cao trong các bệnh nhân bị chấn thương (510\%). Kết quả điều tra tai nạn thương tích năm 2010 (VNIS) trên quy mô toàn quốc cho thây tỷ lệ tai nạn thương tích ở Việt Nam là cao, trong đó nguyên nhân gây tử vong hàng đâu là tai nạn giao thông. Chấn thương hàm mặt thường đòi hỏi phải phẫu thuật để phục hồi giải phẫu, chức năng và thẩm mỹ. Do có cấu trúc giải phấu liên quan trực tiếp đến khoang miệng nên chấn thương hàm mặt có nguy cơ nhiễm trùng cao, gây khó khăn cho công tác điều trị và đôi lúc để lại biến chứng nặng nề. Với bệnh nhân chấn thương hàm mặt, đa số là phẫu thuật cấp cứu trì hoãn, vì vậy, việc chăm sóc vệ sinh răng miệng trước phẫu thuật đối với bệnh nhân là việc làm cần thiết để giảm đau nhức vùng miệng, làm giảm nguy cơ nhiễm trùng, đảm bảo an toàn cho bệnh nhân trong phẫu thuật và tăng cường quá trình liền thương sau phẫu thuật. Để góp phần vào việc tăng hiệu quả phẫu thuật và tăng sự hài lòng ở bệnh nhân chấn thương vùng hàm mặt có chỉ định phẫu thuật, chúng tôi nghiên cứu đề tài 